\title{
Association of the rs7903146 and rs12255372 polymorphisms in the TCF7L2 gene with type 2 diabetes in a population from northeastern Brazil
}

\author{
C.M.A.R. Barros ${ }^{1}$, A.P. Araujo-Neto ${ }^{1}$, T.R. Lopes ${ }^{1}$, M.A.L. Barros ${ }^{1}$, \\ F.J.N. Motta ${ }^{1}$, R. Canalle ${ }^{1}$, L.C.C. Nunes $^{2}$, J.A. Rey ${ }^{3}$, R.R. Burbano ${ }^{4}$, \\ M.A. Lima-Barros ${ }^{5}$, F.K.N. Yoshioka ${ }^{1}$ and G.R. Pinto ${ }^{1}$ \\ ${ }^{1}$ Laboratório de Genética e Biologia Molecular, Universidade Federal do Piauí, \\ Parnaíba, PI, Brasil \\ ${ }^{2}$ Núcleo de Tecnologia Farmacêutica, Universidade Federal do Piauí, Teresina, \\ PI, Brasil \\ ${ }^{3}$ Laboratorio de Oncogenética Molecular, Departamento de Cirugía Experimental, \\ Hospital Universitario “La Paz”, Madrid, España \\ ${ }^{4}$ Laboratório de Citogenética Humana, Universidade Federal do Pará, Belém, \\ PA, Brasil \\ ${ }^{5}$ Tec Lab Medicina Laboratorial, Parnaíba, PI, Brasil \\ Corresponding author: G.R. Pinto \\ E-mail: pintogr@ufpi.edu.br \\ Genet. Mol. Res. 13 (3): 7889-7898 (2014) \\ Received February 28, 2013 \\ Accepted December 2, 2013 \\ Published September 29, 2014 \\ DOI http://dx.doi.org/10.4238/2014.September.29.1
}

ABSTRACT. Approximately 200 million people suffer from type 2 diabetes (T2D) worldwide, and the rapid increase in the prevalence of this disease is likely a result of multiple environmental factors, such as increased food intake and decreased physical activity in genetically predisposed individuals. Different population studies have demonstrated a strong association of two polymorphic variations in the TCF7L2 gene, the noncoding single nucleotide polymorphisms 
(SNPs) rs7903146 (C/T) and rs12255372 (G/T), with T2D. Herein, we analyzed the association of these SNPs with T2D in a population from northeastern Brazil. Our results showed that the genotype and allele frequencies in TCF7L2 rs7903146 and rs12255372 were similar in the patient and control groups $(\mathrm{P}>0.05)$. In addition, the allele frequencies were not significantly associated with T2D risk [rs7903146: odds ratio $(\mathrm{OR})=0.95,95 \%$ confidence interval $(\mathrm{CI})=$ $0.52-1.76, \mathrm{P}=1.00$, and rs12255372: $\mathrm{OR}=1.38,95 \% \mathrm{CI}=0.72-2.62$, $\mathrm{P}=0.41]$. These data suggest that the TCF7L2 SNPs rs7903146 and rs12255372 may not significantly contribute to T2D susceptibility in this population. However, our results may reflect the small number of subjects. Alternatively, these results may be attributable to specific ethnic effects, as most of the previously reported associations were demonstrated with predominantly European populations. To reach a definitive conclusion on the role of such gene variants for T2D in mixed populations, additional efforts are necessary to replicate this study with larger populations from areas with more ethnic heterogeneity.

Key words: Type 2 diabetes; Genetic polymorphisms; TCF7L2; rs7903146; rs12255372; Mixed population

\section{INTRODUCTION}

Diabetes is a complex and heterogeneous disease that is characterized by persistent hyperglycemia caused by absolute or relative insulin deficiency. The different types of diabetes include types 1 and 2 in addition to rare forms of the disease such as gestational diabetes and maturity onset diabetes in youth (MODY) (Kommoju and Reddy, 2011). Type 2 diabetes (T2D) is the most common form of the disease, accounting for approximately $90 \%$ of the diabetes cases worldwide. The onset of T2D typically occurs in people over 40 years of age and is strongly associated with a modern lifestyle. It is one of the most important metabolic diseases and is characterized by different levels of insulin resistance as well as defects in pancreatic beta cell function (Ramachandran et al., 2002). It is estimated that approximately 200 million people suffer from T2D worldwide, and the rapid increase in the prevalence of this disease is likely a result of multiple environmental factors, such as increased food intake and decreased physical activity in genetically predisposed individuals (Stumvoll et al., 2005; Permutt et al., 2005). In the USA, for example, the disease is considered an epidemic and is now the sixth leading cause of death. It is also estimated that there will be a $42 \%$ increase in the number of cases (51 to 72 million) in developed countries and a $170 \%$ increase ( 84 to 228 million) in developing countries, such as Brazil, in the near future. Therefore, it is projected that by $2025,75 \%$ of patients with diabetes will reside in developing countries compared with $62 \%$ in 1995 . In developing countries, most diabetes patients are between 45 and 64 years old, whereas in developed countries, diabetes is commonly observed in patients $\geq 65$ years old (King et al., 1998; Wild et al., 2004).

Upon the completion of the Human Genome Project, the last decade has been marked by a considerable number of research studies around the world that aimed to identify alleles in candidate genes for T2D as well as attempts to find clues to better understand its primary 
pathogenesis, which may generate better strategies for its prevention, diagnosis, and treatment (Imamura and Maeda, 2011).

Seeking the basis for a previously identified linkage signal in a region on the long arm of chromosome 10, Grant et al. (2006) identified a strong association between the DG10S478 microsatellite marker and T2D in samples from Icelandic individuals. In addition, the authors repeated these results in North American and Danish cohorts composed of only Caucasian individuals. The DG10S478 microsatellite is a tetranucleotide repeat with six alleles, which is located in a well-defined 92.1-kb block in linkage disequilibrium (LD) comprised of exon 4 and a portion of two large intronic regions that flank the TCF $7 L 2$ gene.

The TCF7L2 gene spans $215.9 \mathrm{~kb}$ on chromosome 10q25.3 and encodes a transcription factor that was previously associated with blood glucose homeostasis and plays an important role in Wnt signaling (Duval et al., 2000; Yi et al., 2005). Lyssenko et al. (2007) showed that a change in the expression and function of the TCF 2 2 gene prevents the correct functioning of the pancreatic islets, which is most likely due to deregulation of the expression of the $C G C$ gene, which encodes glucagon. Consequently, insulin secretion may decrease and the risk for T2D may increase.

Two other polymorphic variations in the TCF7L2 gene, the noncoding single nucleotide polymorphisms (SNPs) rs7903146 (C/T) and rs $12255372(\mathrm{G} / \mathrm{T})$, are in strong LD with the DG10S478 microsatellite and demonstrate a strong association with T2D (Grant et al., 2006). Florez et al. (2006) reported that the TCF7L2 SNPs rs7903146 and rs12255372 are associated with decreased insulin secretion and an increased risk for T2D among North American individuals with glucose intolerance. These authors recommended that the two variants be genotyped in all studies to confirm these results.

Independent studies have confirmed an association between the TCF7L2 SNPs rs7903146 and/or rs12255372 and T2D in various populations from countries such as England, Finland, Poland, France, Germany, the Netherlands, Sweden, Iran, India, Japan, China, and Tunisia (Cauchi et al., 2006; Groves et al., 2006; Saxena et al., 2006; Scott et al., 2006; Horikoshi et al., 2007; Mayans et al., 2007; van Vliet-Ostaptchouk al., 2007; Ezzidi et al., 2009; Gupta et al., 2010; Wen et al., 2010; Palizban et al., 2012). However, conflicting results have been reported in populations from China, Saudi Arabia, and the United Arab Emirates, as well as in the Native American population of North America (Guo et al., 2007; Alsmadi et al., 2008; Ren et al., 2008; Saadi et al., 2008). Moreover, although an association between the TCF7L2 SNPs rs7903146 and rs12255372 and T2D has been investigated in several studies of Caucasian populations, there have been relatively few studies of mixed populations, such as Brazilians (Marquezine et al., 2008; Franco et al., 2011; Barra et al., 2012; Furgeri et al., 2012).

Herein, we investigated the association between the SNPs rs7903146 and rs 12255372 with T2D in a mixed population from northeastern Brazil to confirm the role of different TCF7L2 gene variants in different populations.

\section{MATERIAL AND METHODS}

\section{Study population}

Two hundred and twenty unrelated individuals in the general population from Parnaíba, Piauí State, Brazil, were included in this study. The control group consisted of 110 healthy 
subjects who were not diagnosed with T2D or any associated conditions according to clinical and laboratory examinations. The patient group consisted of 110 individuals who were diagnosed with T2D according to the World Health Organization (WHO) criteria (random plasma glucose $>200 \mathrm{mg} / \mathrm{dL}$ and/or levels of fasting plasma glucose $>126 \mathrm{mg} / \mathrm{dL}$ ). The laboratory data (HbA1c, fasting glucose, high-density lipoprotein cholesterol, total cholesterol, and triglyceride levels) and the degree of obesity using the body mass index [BMI; defined as weight (kg)/ height $\left(\mathrm{m}^{2}\right)$ ] for each participant were analyzed (Table 1). To participate in the study, the individuals in the patient and control groups signed informed consent forms, and the procedures were approved by the Universidade Federal do Piauí Ethics Committee in Research.

Table 1. Clinical and biochemical characteristics of patients with type 2 diabetes and healthy controls.
\begin{tabular}{lccc}
\hline Characteristics & Patients & Controls & P \\
\hline Male/female ratio & $110(33 / 77)$ & $110(40 / 70)$ & 0.32 \\
Age during the study (years) & $61.0 \pm 14.0$ & $61.3 \pm 13.9$ & 1.00 \\
BMI [weight (kg)/height (m) ${ }^{2}$ ] & $26.8 \pm 4.9$ & $25.0 \pm 4.2$ & 0.92 \\
Fasting glucose (mg/dL) & $187.5 \pm 91.7$ & $96.0 \pm 18.6$ & 40.001 \\
HbAlc (\%) & $8.2 \pm 2.7$ & $54.6 \pm 0.9$ & $<0.001$ \\
HDL cholesterol (mg/dL) & $52.4 \pm 27.6$ & $218.0 \pm 42$ & $<0.001$ \\
Total cholesterol (mg/dL) & $234.0 \pm 57.6$ & $171.9 \pm 104.9$ & $<0.001$ \\
Triglycerides (mg/dL) & $244.5 \pm 204.0$ & $<001$ \\
\hline
\end{tabular}

Data are the means \pm standard deviation; $\mathrm{BMI}=$ body mass index; HbA1c $=$ glycated haemoglobin (glucose bound to hemoglobin).

\section{DNA extraction and genotyping}

Genomic DNA was extracted from the subjects' peripheral blood leukocytes using the Wizard Genomic Kit (Promega Inc., USA) in accordance with manufacturer instructions. After isolation, the DNA concentration was determined using a Biospec-Nano Spectrophotometer (Shimadzu, Japan). The genotyping was performed using polymerase chain reaction (PCR) followed by enzymatic digestion with restriction endonucleases (RFLP).

PCRs for the TCF7L2 SNPs rs7903146 and rs12255372 were performed using the following cycle conditions: $5 \mathrm{~min}$ at $94^{\circ} \mathrm{C} ; 35$ cycles of $30 \mathrm{~s}$ at $94^{\circ} \mathrm{C}, 30 \mathrm{~s}$ at $58^{\circ} \mathrm{C}$, and $30 \mathrm{~s}$ at $72^{\circ} \mathrm{C}$; and a final extension at $72^{\circ} \mathrm{C}$ for $5 \mathrm{~min}$.

For rs7903146 genotyping, PCR was performed using the following primers: 5'-ACAATTAGAGAGCTAAGCACTTTTTAGGTA-3' (forward) and 5'-GTGAAGTGCCCA AGCTTCTC-3' (reverse). After amplification, the 188-bp PCR products were digested with 2 $\mathrm{U} R s a \mathrm{I}$ restriction enzyme (NEB, USA) at $37^{\circ} \mathrm{C}$ for $4 \mathrm{~h}$. The $R s a \mathrm{I}$ enzyme recognizes the restriction site 5'-GT $\boldsymbol{\nabla}$ AC-3' with the rs $7903146 \mathrm{C}$ allele and produces two fragments, 159 and $29 \mathrm{bp}$, whereas the rs7903146 T allele (mutant) is not cleaved, and its PCR product remains the original size (188 bp).

For genotyping rs 12255372 , PCR was performed using the following primers: 5'-GAGGTGTACTGGAAACTAAGGC-3' (forward) and 5'-GAGGCTGAATCTGGCACTC A-3' (reverse). After amplification, the 226-bp PCR products were digested with $2 \mathrm{U}$ Tsp509I enzyme (Thermo Scientific, USA) at $65^{\circ} \mathrm{C}$ for $4 \mathrm{~h}$. For the rs $12255372 \mathrm{~T}$ (mutant) allele, the Tsp509I enzyme recognizes the 5'- $\mathbf{\nabla}$ AATT-3' restriction site and cleaves the PCR product in two places because the PCR products have a recognition site for the enzyme; consequently, the digestion yields three fragments of 17, 75, and $134 \mathrm{bp}$. Moreover, the rs $12255372 \mathrm{G}$ (wild 
type) allele PCR product is cleaved at only one site, resulting in two fragments, 75 and $151 \mathrm{bp}$. To visualize the digestion products from both SNPs, the DNA fragments were electrophoresed on an $8 \%$ acrylamide:bisacrylamide (29:1) system and stained with silver nitrate. PCRRFLP quality control was performed by randomly selecting $20 \%$ of the samples for re-genotyping by an independent technician. The correlation observed for the genotyping assays was $100 \%$.

\section{Statistical analysis}

The chi-square test was used to determine whether the genotype distributions were in Hardy-Weinberg equilibrium. The genotypic and allelic frequencies were compared between the diabetic patients and controls using chi-square and Fisher exact tests, respectively. The odds ratios (ORs) and 95\% confidence intervals (CIs) were calculated using a logistic regression model. Statistical significance was determined at $\mathrm{P}<0.05$, and the analyses were performed using the BioStat 5.3 software (Mamirauá Institute, Brazil). The statistical analyses for $\mathrm{LD}$, haplotype frequencies, and multiple test corrections per 1000 random permutations were performed using the Haploview 4.2 software (Barrett et al., 2005).

\section{RESULTS}

The success rates for genotyping the TCF7L2 SNPs rs7903146 and rs 12255372 were 98.64 and $97.73 \%$, respectively. The allele and genotype frequencies were in Hardy-Weinberg equilibrium for both SNPs.

The genotype and allele frequencies for the TCF7L2 SNP rs7903146 allele did not differ significantly between the patients and controls. The rs $7903146 \mathrm{~T}$ allele frequency for the controls was $29 \%$, whereas it was $28 \%$ in the patients $(\mathrm{P}=1.00)$. The $\mathrm{C} / \mathrm{C}, \mathrm{C} / \mathrm{T}$, and T/T genotype frequencies for the controls were 53,37 , and $10 \%$, respectively, whereas the frequencies were 49,45 , and $6 \%$, respectively, in patients $(\mathrm{P}=0.30)$. Using the $\mathrm{CC}$ genotype as a reference, the OR analysis showed that the $\mathrm{C} / \mathrm{T}, \mathrm{T} / \mathrm{T}$, and $\mathrm{C} / \mathrm{T}+\mathrm{T} / \mathrm{T}$ genotypes were not associated with an increased risk for T2D in the population studied $(\mathrm{C} / \mathrm{T}$ : $\mathrm{OR}=0.75,95 \% \mathrm{CI}=0.43-1.31$, $\mathrm{P}=0.38 ; \mathrm{T} / \mathrm{T}: \mathrm{OR}=1.67,95 \% \mathrm{CI}=0.58-4.85, \mathrm{P}=0.48 ; \mathrm{C} / \mathrm{T}+\mathrm{T} / \mathrm{T}: \mathrm{OR}=0.85,95 \% \mathrm{CI}=0.50-$ $1.44, \mathrm{P}=0.64)($ Table 2).

The genotypic and allelic frequencies for the TCF7L2 SNP rs12255372 did not differ significantly between the patients and controls. The rs $12255372 \mathrm{~T}$ allele frequency in controls was $22 \%$, whereas it was $28 \%(\mathrm{P}=0.41)$ in patients. The $\mathrm{G} / \mathrm{G}, \mathrm{G} / \mathrm{T}$, and $\mathrm{T} / \mathrm{T}$ genotype frequencies were $62.0,31.5$, and $6.5 \%$, respectively, for the controls, and were $51.4,41.1$, and $7.5 \%$, respectively, for the patients $(\mathrm{P}=0.31)$. Using the $\mathrm{GG}$ genotype as a reference, the $\mathrm{OR}$ analysis showed that the $\mathrm{G} / \mathrm{T}, \mathrm{T} / \mathrm{T}$, and $\mathrm{G} / \mathrm{T}+\mathrm{T} / \mathrm{T}$ genotypes are not associated with an increased risk of $\mathrm{T} 2 \mathrm{D}$ in the population $(\mathrm{G} / \mathrm{T}: \mathrm{OR}=0.63,95 \% \mathrm{CI}=0.36-1.12, \mathrm{P}=0.16 ; \mathrm{T} / \mathrm{T}: \mathrm{OR}=0.72,95 \% \mathrm{CI}$ $=0.24-2.10, \mathrm{P}=0.74 ; \mathrm{G} / \mathrm{T}+\mathrm{T} / \mathrm{T}: \mathrm{OR}=0.65,95 \% \mathrm{CI}=0.38-1.11, \mathrm{P}=0.15)($ Table 2$)$.

The LD analysis showed that alleles for the rs7903146 (C/T) and rs12255372 (G/T) SNPs are moderately associated $\left(D^{\prime}=0.65 ; R^{2}=0.36\right)$. Four haplotypes were constructed for these variations, and none differed significantly between the control and patient groups $(\mathrm{P}>$ 0.05). For example, the TT haplotype frequency, which carries the two alleles with the lowest frequency and were previously shown to be risk alleles for T2D, was $19.9 \%$ in the patient group and $17.8 \%$ in the control group $(\mathrm{P}=0.93 ; 1000$ permutations) (Table 3$)$. 
Table 2. Genetic characteristics of the patients with type 2 diabetes and healthy controls.

\begin{tabular}{|c|c|c|c|c|c|}
\hline Variables & Patients & Controls & $\mathrm{P}^{*}$ & OR $(95 \% \mathrm{CI})$ & $P$ \\
\hline Rs 7903146 & $\mathrm{~N}=108(\%)$ & $\mathrm{N}=109(\%)$ & & & \\
\hline \multicolumn{6}{|l|}{ Genotype } \\
\hline $\mathrm{C} / \mathrm{C}$ & $53(49.0)$ & $58(53.2)$ & & & \\
\hline $\mathrm{C} / \mathrm{T}$ & $49(45.4)$ & $40(36.7)$ & & $0.75(0.43-1.31)$ & 0.38 \\
\hline $\mathrm{T} / \mathrm{T}$ & $6(5.6)$ & $11(10.1)$ & 0.30 & $1.67(0.58-4.85)$ & 0.48 \\
\hline $\mathrm{C} / \mathrm{T}+\mathrm{T} / \mathrm{T}$ & & & & $0.85(0.50-1.44)$ & 0.64 \\
\hline \multicolumn{6}{|l|}{ Allele } \\
\hline $\mathrm{C}$ & $155(72.0)$ & $156(71.0)$ & & & \\
\hline $\mathrm{T}$ & $61(28.0)$ & $62(29.0)$ & 1.00 & $0.95(0.52-1.76)$ & 1.00 \\
\hline Rs 12255372 & $\mathrm{~N}=107(\%)$ & $\mathrm{N}=108(\%)$ & & & \\
\hline \multicolumn{6}{|l|}{ Genotype } \\
\hline $\mathrm{G} / \mathrm{G}$ & $55(51.4)$ & $67(62.0)$ & & & \\
\hline $\mathrm{G} / \mathrm{T}$ & $44(41.1)$ & $34(31.5)$ & 0.31 & $0.63(0.36-1.12)$ & 0.16 \\
\hline $\mathrm{T} / \mathrm{T}$ & $8(7.5)$ & $7(6.5)$ & & $0.72(0.24-2.10)$ & 0.74 \\
\hline $\mathrm{G} / \mathrm{T}+\mathrm{T} / \mathrm{T}$ & 52 & 41 & & $0.65(0.38-1.11)$ & 0.15 \\
\hline \multicolumn{6}{|l|}{ Allele } \\
\hline G & $154(72)$ & $168(78)$ & & & \\
\hline $\mathrm{T}$ & $60(28)$ & $48(22)$ & 0.41 & $1.38(0.72-2.62)$ & 0.41 \\
\hline
\end{tabular}

*P value from chi-square or Fisher exact tests. $\mathrm{OR}=$ odds ratio; $95 \% \mathrm{CI}=95 \%$ confidence interval.

Table 3. Haplotype frequency for the rs7903146 (C/T) and rs 12255372 (G/T) SNPs in the patient and control groups.

\begin{tabular}{lcccc}
\hline Haplotypes & Patients (\%) & Controls (\%) & P & P* \\
\hline CG & 62.8 & 67.3 & 0.33 & 0.71 \\
TT & 19.9 & 17.8 & 0.58 & 0.92 \\
TG & 8.9 & 10.6 & 0.54 & 0.91 \\
CT & 8.4 & 4.3 & 0.07 & 0.18 \\
\hline
\end{tabular}

*Adjusted P values after 1000 permutations.

\section{DISCUSSION}

T2D is becoming an epidemic in many countries, and consequently, a public health problem worldwide given the complications observed in patients. Thus, studies on the disease are increasingly important for establishing an early diagnosis strategy, efficient population screening methods, more effective therapies, and better preventative measures. The recent dramatic increase in the number of diabetic patients strongly indicates that factors related to lifestyle, the growing urbanization of cities, and a sedentary lifestyle in modern human populations may play roles in triggering the genetic factors associated with T2D. Therefore, it is important to understand the genetic aspects underlying this complex disease in order to rapidly implement preventive measures (Ramachandran et al., 2002).

The importance of genetic factors in the etiology of T2D was well established based on family and twin studies (Groop et al., 1996; Poulsen et al., 1999). However, the genes involved in T2D have been shown to have only modest effects on disease risk and often generate inconsistent results in studies aiming to replicate the data (Hattersley and McCarthy, 2005). For example, the results of only a few genomic variation association studies, such as those that assessed SNPs in the PPARG Pro12Ala, KCNJ11 Glu23Lys, and CAPN10 genes have been convincingly replicated in different ethnic groups (Altshuler et al., 2000; Gloyn et al., 2003; 
Weedon et al., 2003). Subsequently, SNPs in the region with the TCF7L2 gene were strongly associated with T2D (Cauchi et al., 2006; Grant et al., 2006).

Herein, we analyzed the association of the TCF7L2 SNPs rs7903146 and rs 12255372 with T2D in a population from northeastern Brazil. Our results showed that the genotype and allele frequencies in the TCF7L2 SNPs rs 7903146 and rs 12255372 were similar in the patient and control groups $(\mathrm{P}>0.05)$. In addition, the allele frequencies for these variations were not significantly associated with a risk for T2D (rs7903146: $\mathrm{OR}=0.95,95 \% \mathrm{CI}=0.52-1.76, \mathrm{P}=$ 1.00 and rs $12255372: \mathrm{OR}=1.38,95 \% \mathrm{CI}=0.72-2.62, \mathrm{P}=0.41$ ). These data suggest that the TCF7L2 SNPs rs7903146 and rs 12255372 may not significantly contribute to T2D susceptibility in this population.

Variations in the TCF7L2 gene were initially described as contributing to T2D pathogenesis predominantly in European populations (Cauchi et al., 2006; Groves et al., 2006; Saxena et al., 2006; Scott et al., 2006; Mayans et al., 2007; van Vliet-Ostaptchouk et al., 2007). However, new studies in different ethnic groups have reported inconsistent results, including in Chinese and North American Native American populations (Guo et al., 2007; Ren et al., 2008). These studies were supported by a lack of association between T2D and the TCF7L2 SNP rs7903146 and a marginal association of rs 12255372 in a United Arab Emirates population (Saadi et al., 2008). In addition, there was no association of either SNP with Saudi Arabian diabetic patients (Alsmadi et al., 2008).

Brazil has one of the most heterogeneous populations in the world, resulting from more than five centuries of interbreeding among people from three continents, including European settlers (primarily Portuguese), African slaves, and Native Americans (Parra et al., 2003). In southeastern Brazil, Marquezine et al. (2008) reported an association between the rs7903146 T allele in the TCF7L2 gene and a 1.57 times increased risk for T2D in a cohort of patients with coronary heart disease. These results were corroborated by Barra et al. (2012) in a diabetic population from the central western region of Brazil. As for the TCF7L2 SNP rs12255372, Furgeri et al. (2012) failed to find an association of this variant with increased risk for T2D in patients with cystic fibrosis in southeastern Brazil. Likewise, a study consisting of patients from the same region conducted by Franco et al. (2011) reported no association of the TCF7L2 SNPs rs12255372 and rs7903146 with T2D in a Japanese-Brazilian population. Our results from a population in northeastern Brazil corroborate the findings of Furgeri et al. (2012) and Franco et al. (2011), and contribute to the conclusion that the replication of the results in mixed populations does not follow the same pattern as that observed in more homogeneous populations, such as the European population.

With respect to haplotype frequencies, Alsmadi et al. (2008) demonstrated a moderate association between the TCF7L2 SNPs rs7903146 and rs12255372 in a Saudi Arabian population $\left(D^{\prime}=0.80 ; R^{2}=0.66\right)$. In addition, the authors observed a significant difference for the CT haplotype between patients with T2D and healthy controls $(\mathrm{P}=0.03)$. However, the authors advised caution in interpreting these results given the low statistical power for this observation because the CT haplotype was observed in only 38 of the 522 patients analyzed. Likewise, our results demonstrated a moderate association of the TCF7L2 SNPs rs7903146 and rs12255372 $\left(D^{\prime}=0.65 ; R^{2}=0.36\right)$ and a trend of the association of the CT haplotype with the studied population $(\mathrm{P}=0.07)$. However, this association decreased significantly after correcting for multiple tests per 1000 random permutations $(\mathrm{P}=0.18)$.

Despite reports for a strong association of the TCF7L2 gene SNPs with T2D in different studies, it is still unclear how these intronic variants confer susceptibility to the disease. 
Studies suggest that the TCF7L2 gene plays an important role in maintaining the mass and function of pancreatic beta cells. The product of this gene is a transcription factor that may play a critical role in beta cell proliferation, protection against apoptosis, and insulin secretion (Loder et al., 2008; Shu et al., 2008). Gaulton et al. (2010) conducted an extensive functional study on the SNP rs7903146 in the TCF7L2 gene and reported that this variant affects susceptibility to T2D by altering the cis regulation and local chromatin structure in pancreatic islets cells. More recently, Shu et al. (2012) observed a correlation between the pancreatic expression of the TCF7L2 gene with beta cell proliferation and the regeneration of such cells in various murine models of diabetes. In addition, the authors demonstrated that the overexpression of the TCF7L2 gene in human exocrine pancreatic tissue induced a beta cell phenotype and insulin production in ductal epithelial cells.

\section{CONCLUSION}

The partial results herein represent the first analysis of the TCF7L2 SNPs rs7903146 and rs 12255372 in patients with T2D in a racially mixed population from northeastern Brazil. Although the genotype and allele frequencies were similar in the patient and control groups $(\mathrm{P}$ $>0.05$ ) for both variants, we cannot ignore the possibility that our results may reflect the small number of subjects. Alternatively, such results may be attributable to specific ethnic effects because most of the previously reported associations were found in studies of predominantly European populations.

Thus, although we have not identified a significant association for the TCF7L2 SNPs rs7903146 and rs12255372, the weak association cannot be dismissed. For a definitive conclusion on the role of these gene variants in T2D in mixed populations, additional efforts are necessary to reproduce the methodology adopted herein using larger populations from areas with more ethnic heterogeneity.

\section{ACKNOWLEDGMENTS}

Research supported by the National Counsel of Technological and Scientific Development (Conselho Nacional de Desenvolvimento Científico e Tecnológico, CNPq; grant \#502193/2009-3) and by the Coordination of Improvement of Higher Education (Coordenação de Aperfeiçoamento de Pessoal de Nível Superior; CAPES).

\section{REFERENCES}

Alsmadi O, Al-Rubeaan K, Mohamed G, Alkayal F, et al. (2008). Weak or no association of TCF7L2 variants with type 2 diabetes risk in an Arab population. BMC Med. Genet. 9: 72.

Altshuler D, Hirschhorn JN, Klannemark M, Lindgren CM, et al. (2000). The common PPARgamma Pro12Ala polymorphism is associated with decreased risk of type 2 diabetes. Nat. Genet. 26: 76-80.

Barra GB, Dutra LA, Watanabe SC, Costa PG, et al. (2012). Association of the rs 7903146 single nucleotide polymorphism at the Transcription Factor 7-like 2 (TCF7L2) locus with type 2 diabetes in Brazilian subjects. Arq. Bras. Endocrinol. Metabol. 56: 479-484.

Barrett JC, Fry B, Maller J and Daly MJ (2005). Haploview: analysis and visualization of LD and haplotype maps. Bioinformatics 21: 263-265.

Cauchi S, Meyre D, Dina C, Choquet H, et al. (2006). Transcription factor TCF7L2 genetic study in the French population: expression in human beta-cells and adipose tissue and strong association with type 2 diabetes. Diabetes 55: 2903-2908. 
Duval A, Busson-Leconiat M, Berger R and Hamelin R (2000). Assignment of the TCF-4 gene (TCF7L2) to human chromosome band 10q25.3. Cytogenet. Cell Genet. 88: 264-265.

Ezzidi I, Mtiraoui N, Cauchi S, Vaillant E, et al. (2009). Contribution of type 2 diabetes associated loci in the Arabic population from Tunisia: a case-control study. BMC Med. Genet. 10: 33.

Florez JC, Jablonski KA, Bayley N, Pollin TI, et al. (2006). TCF7L2 polymorphisms and progression to diabetes in the diabetes prevention program. N. Engl. J. Med. 355: 241-250.

Franco LF, Crispim F, Pereira AC and Moises RS (2011). Variants of transcription factor 7-like 2 (TCF7L2) gene and incident glucose intolerance in Japanese-Brazilians. Braz. J. Med. Biol. Res. 44: 240-244.

Furgeri DT, Marson FA, Ribeiro AF and Bertuzzo CS (2012). Association between the IVS4G > T mutation in the TCF7L2 gene and susceptibility to diabetes in cystic fibrosis patients. BMC Res. Notes 5: 561.

Gaulton KJ, Nammo T, Pasquali L, Simon JM, et al. (2010). A map of open chromatin in human pancreatic islets. Nat. Genet. 42: 255-259.

Gloyn AL, Weedon MN, Owen KR, Turner MJ, et al. (2003). Large-scale association studies of variants in genes encoding the pancreatic $\beta$-cell KATP channel subunits Kir6.2 (KCNJ11) and SUR1 (ABCC8) confirm that the KCNJ11 E23K variant is associated with type 2 diabetes. Diabetes 52: 568-572.

Grant SF, Thorleifsson G, Reynisdottir I, Benediktsson R, et al. (2006). Variant of transcription factor 7-like 2 (TCF7L2) gene confers risk of type 2 diabetes. Nat. Genet. 38: 320-323.

Groop L, Forsblom C, Lehtovirta M, Tuomi T, et al. (1996). Metabolic consequences of a family history of NIDDM (the Botnia study): evidence for sex-specific parental effects. Diabetes 45: 1585-1593.

Groves CJ, Zeggini E, Minton J, Frayling TM, et al. (2006). Association analysis of 6,736 U.K. subjects provides replication and confirms TCF7L2 as a type 2 diabetes susceptibility gene with a substantial effect on individual risk. Diabetes 55: 2640-2644.

Guo T, Hanson RL, Traurig M, Muller YL, et al. (2007). TCF7L2 is not a major susceptibility gene for type 2 diabetes in Pima Indians: analysis of 3,501 individuals. Diabetes 56: 3082-3088.

Gupta V, Khadgawat R, Ng HK, Kumar S, et al. (2010). A validation study of type 2 diabetes-related variants of the TCF7L2, HHEX, KCNJ11, and ADIPOQ genes in one endogamous ethnic group of north India. Ann. Hum. Genet. 74: 361-368.

Hattersley AT and McCarthy MI (2005). What makes a good genetic association study? Lancet 366: 1315-1323.

Horikoshi M, Hara K, Ito C, Nagai R, et al. (2007). A genetic variation of the transcription factor 7-like 2 gene is associated with risk of type 2 diabetes in the Japanese population. Diabetologia 50: 747-751.

Imamura M and Maeda S (2011). Genetics of type 2 diabetes: the GWAS era and future perspectives [Review]. Endocr. J. 58: 723-739.

King H, Aubert RE and Herman WH (1998). Global burden of diabetes, 1995-2025: prevalence, numerical estimates, and projections. Diabetes Care 21: 1414-1431.

Kommoju UJ and Reddy BM (2011). Genetic etiology of type 2 diabetes mellitus: a review. Int. J. Diabetes Dev. Ctries. 31: 51-64.

Loder MK, da Silva Xavier G, McDonald A and Rutter GA (2008). TCF7L2 controls insulin gene expression and insulin secretion in mature pancreatic beta-cells. Biochem. Soc. Trans. 36: 357-359.

Lyssenko V, Lupi R, Marchetti P, Del Guerra S, et al. (2007). Mechanisms by which common variants in the TCF7L2 gene increase risk of type 2 diabetes. J. Clin. Invest. 117: 2155-2163.

Marquezine GF, Pereira AC, Sousa AG, Mill JG, et al. (2008). TCF7L2 variant genotypes and type 2 diabetes risk in Brazil: significant association, but not a significant tool for risk stratification in the general population. BMC Med. Genet. 9: 106.

Mayans S, Lackovic K, Lindgren P, Ruikka K, et al. (2007). TCF7L2 polymorphisms are associated with type 2 diabetes in northern Sweden. Eur. J. Hum. Genet. 15: 342-346.

Palizban A, Nikpour M, Salehi R and Maracy MR (2012). Association of a common variant in TCF7L2 gene with type 2 diabetes mellitus in a Persian population. Clin. Exp. Med. 12: 115-119.

Parra FC, Amado RC, Lambertucci JR, Rocha J, et al. (2003). Color and genomic ancestry in Brazilians. Proc. Natl. Acad. Sci. U. S. A. 100: 177-182.

Permutt MA, Wasson J and Cox N (2005). Genetic epidemiology of diabetes. J. Clin. Invest. 115: 1431-1439.

Poulsen P, Kyvik KO, Vaag A and Beck-Nielsen H (1999). Heritability of type II (non-insulin-dependent) diabetes mellitus and abnormal glucose tolerance - a population-based twin study. Diabetologia 42: 139-145.

Ramachandran A, Snehalatha C and Viswanathan V (2002). Burden of type 2 diabetes and its complications - The Indian scenario. Curr. Sci. 83: 1471-1476.

Ren Q, Han XY, Wang F, Zhang XY, et al. (2008). Exon sequencing and association analysis of polymorphisms in TCF7L2 with type 2 diabetes in a Chinese population. Diabetologia 51: 1146-1152. 
Saadi H, Nagelkerke N, Carruthers SG, Benedict S, et al. (2008). Association of TCF7L2 polymorphism with diabetes mellitus, metabolic syndrome, and markers of beta cell function and insulin resistance in a population-based sample of Emirati subjects. Diabetes Res. Clin. Pract. 80: 392-398.

Saxena R, Gianniny L, Burtt NP, Lyssenko V, et al. (2006). Common single nucleotide polymorphisms in TCF7L2 are reproducibly associated with type 2 diabetes and reduce the insulin response to glucose in nondiabetic individuals. Diabetes 55: 2890-2895.

Scott LJ, Bonnycastle LL, Willer CJ, Sprau AG, et al. (2006). Association of transcription factor 7-like 2 (TCF7L2) variants with type 2 diabetes in a Finnish sample. Diabetes 55: 2649-2653.

Shu L, Sauter NS, Schulthess FT, Matveyenko AV, et al. (2008). Transcription factor 7-like 2 regulates $\beta$-cell survival and function in human pancreatic islets. Diabetes 57: 645-653.

Shu L, Zien K, Gutjahr G, Oberholzer J, et al. (2012). TCF7L2 promotes beta cell regeneration in human and mouse pancreas. Diabetologia 55: 3296-3307.

Stumvoll M, Goldstein BJ and van Haeften TW (2005). Type 2 diabetes: principles of pathogenesis and therapy. Lancet 365: 1333-1346.

van Vliet-Ostaptchouk JV, Shiri-Sverdlov R, Zhernakova A, Strengman E, et al. (2007). Association of variants of transcription factor 7-like 2 (TCF7L2) with susceptibility to type 2 diabetes in the Dutch breda cohort. Diabetologia 50: 59-62.

Weedon MN, Schwarz PE, Horikawa Y, Iwasaki N, et al. (2003). Meta-analysis and a large association study confirm a role for calpain-10 variation in type 2 diabetes susceptibility. Am. J. Hum. Genet. 73: 1208-1212.

Wen J, Ronn T, Olsson A, Yang Z, et al. (2010). Investigation of type 2 diabetes risk alleles support CDKN2A/B, CDKAL1, and TCF7L2 as susceptibility genes in a Han Chinese cohort. PLoS One 5: e9153.

Wild S, Roglic G, Green A, Sicree R, et al. (2004). Global prevalence of diabetes: estimates for the year 2000 and projections for 2030. Diabetes Care 27: 1047-1053.

Yi F, Brubaker PL and Jin T (2005). TCF-4 mediates cell type-specific regulation of proglucagon gene expression by betacatenin and glycogen synthase kinase-3beta. J. Biol. Chem. 280: 1457-1464. 